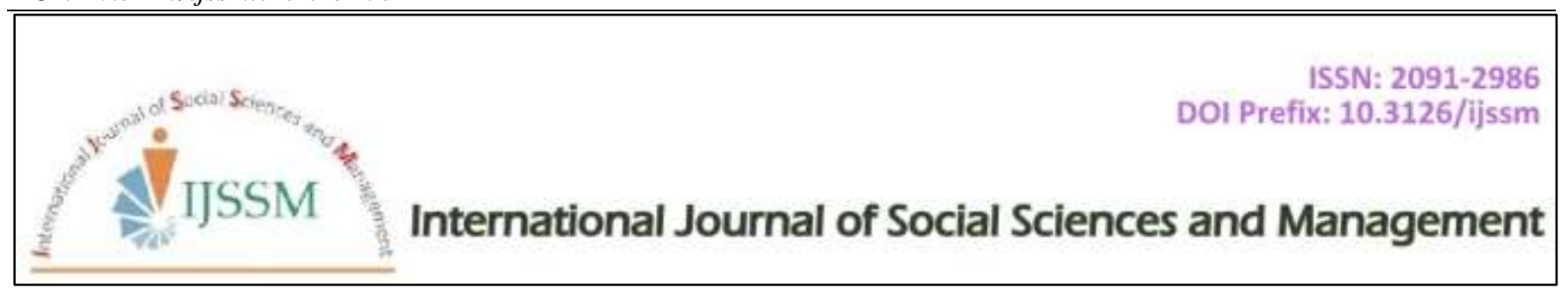

Case Study

\title{
An Assessment on Factors Affecting Student -Teachers' Inferential Understanding in Reading Comprehension Practice: The Case of GilgelBeles College of Teacher Education, BenishangualGumuz Region
}

\author{
Shewa Basizew* \\ Department of English Language (TEFLL), Assosa University, Ethiopia \\ *Email: -fikershewa@gmail.com \\ Mobile: 251-09-12682369/09-23235744
}

\begin{abstract}
This study aimed to assess, identify and analyze factors affecting student-teachers' inferential understanding in the reading comprehension practices in the English department of GilgelBeles College of teachers Education in BenishangulGumuz Regional State. It attempted to answer the following basic questions: - what factors influence inferential understanding, and how they influence inferential understanding. In order to achieve the objectives, a sample population is taken from the studentteachers and all three English language teachers in the department. Data collection instruments included questionnaire, interview and classroom observation. The collected data was analyzed quantitatively for close ended questions and qualitatively for open-ended questions, interviews and classroom observations. The study reveals that the main impediments that hinder student-teachers' inferential understanding while practicing for reading comprehension are lack of regular practice, poor high school background knowledge, the physical environment ( high temperature), lack of motivation, large class size and lack of teacher commitment in supporting students, loss of attention towards implied meanings and problem of using reading strategies effectively. The studies also indicate that, student -teachers need to develop their motivation and to practice reading activities more frequently. Furthermore, teachers need to commit to providing their students with more practice making use of authentic materials. In addition, installing fans in college classrooms would improve learning conditions and building more classrooms would help limit the number of students in a class.
\end{abstract}

Keywords: Inferential Understanding; Practice; Reading; Comprehension; BenishangulGumuz

\section{The Background and the Rational of the Study}

In general, reading comprehension and in particular reading for inferential meanings, is the process of constructing meaning from the text provided to learners. At its broad sense,the goal of all reading instruction is ultimately targeted at helping readers comprehend the text. Hence, reading comprehension involves at least two bodies:-the reader and the writer. The process of comprehending involves decoding the writer's words-Inferring meanings and then using back ground knowledge to construct approximate understanding of the writer's messageInferential meanings (Lenz,1999).It involves much more than readers' responses to text. Besides, reading comprehension especially reading for inferential meanings is the ongoing understanding of what is read while engaging on reading activities. It is the ability that transforms written text into meaningful understanding. It requires the reader to be able to read the words, know the vocabulary, be relatively fluent and understand the language structure underlying the text. In addition, a reader must be able to relate the current text being read to the previous text in order to develop a clear understanding of the entire passage (Klingner et $a l, 2007$ ).

According to Nuttal (1996) cited in (Girma, 1994) literally the term "inference "stands for something derived by reasoning, something that is not directly stated in the text, but only suggested. In this kind of reading, the reader needs to see or go beyond what is directly stated. It also needs the readers' interpretation; even though the interpretation is partly based on what is given in the reading text and partly on what the reader knows-the prior knowledge of the reader. In reading for inferential understanding the reader infers or deduces meanings from the text by himself or herself, make judgments about what the reader is showing-agreement, 
disagreement, saying something is right or wrong, bad or good and doing something on the basis of what the reader has read already etc. Therefore, inferring information is more difficult than locating stated information. This is because, the reader has to make mental association between external (the reading material) and the internal source (background knowledge).

Hence, it can be drawn as inferential comprehension questions measure interpretation. These items require you to read between the lines or even "beyond the lines. Making an inference requires the reader to combine prior knowledge and experience with passage information. Making an inference requires using information that is explicit in a passage, determining which ideas are relevant to answering a particular question, and combining those ideas to create something unique, something that is implied by the information at hand.

Reading for inferential understanding is such an important skill throughout students' life. So that, student-teachers in GilgelBeles College of Teachers Education should have practiced good reading comprehension skills that would facilitate and develop their knowledge of understanding inferential meanings. This in turn increases their ability of understanding comprehension questions like implied meanings that the writer addressed to convey in his or message.

It is obvious that, reading is the principal source of knowledge particularly in academic discipline. To understand, interpret and analyze a subject one has to be strong enough and show his or devotion in reading skills. Conversely, poor reading capacity implies lack of understanding -grasping the theme of the discussions in English classes, which can vigorously influence the quality of education in primary schools at its broad sense. The quality can be affected, this is because it is those studentteachers who are going to be assigned as teacher to primary schools in the region. Therefore, the researcher has commonly observed the above problems while delivering the lesson in relation to reading for inferential meanings. Thus, it is crucial that solution need to be searched to overcome the obstacles to reading for inferential understanding in comprehension practice in English language classes in the college-GilgelBeles College.

Meanwhile, the student teachers who joined GilgelBeles College were not competent enough in English language, in understanding and interpreting inferential meanings in the reading text. This was manifested in the form of difficulty in responding to questions raised from reading comprehension activities, because of inability to understand the idea of the reading comprehension questions from this text. Moreover, the problem of identifying and using appropriate reading techniques while reading for inferential understanding were still commonly observed in English language classes.

Therefore, this study will be expected to contributesome to the existing gap by making discussion in line with the following objectives:-to assess the factors that affect student-teachers' inferential understanding ability in reading comprehension skills; and to examine how the factors affect student-teachers' inferential understanding ability in reading comprehension skills.

\section{Methodology}

This section deals with the research setting, research design, participants, sampling procedure, the data collection instruments and techniques of data analysis that were used in conducting the study. The study was conducted on year three English department students in GilgelBeles College of Teachers in BenishangulGumuz Regional State. GilgelBeles College is found in Metekel Zone in Madura district in the region or in the former western Gojam part of the country. The researcher has chosen to work on this problem, since he had observed that student-teachers inferring meanings for inferential understanding was extremely poor and poor. Besides to this, the researcher's residence was there, and data collection was facilitated because of easy access to the interviewees and students in the college.

This study is a descriptive case study on assessing factors affecting student-teachers' inferential understanding in reading comprehension skills, in English language classes. Because, it examines factors that cause problems for student-teachers inferential understanding in reading comprehension. Both qualitative and quantitative methods were used. Qualitative methods were used to interpret, clarify and justify the data collected through interviews and questionnaires (open-ended questions) and the classroom observation. Interviews comprised open-ended questions which mostly assessed the feelings, beliefs and attitudes of students and teachers which required justification and clarification by the researcher in the presentation and in the analysis part of the study, whereas a quantitative approach was used to show the outcome in frequency and percentage which were duly shown on a table. Because, a quantitative approach deals with close-ended questions, which revealed the fact (data) that did not require justification or clarification of the researcher, outcome can be quantified in percentages and frequency indicators.

The third year English language department students and English language teachers in the college were the participants of this study. Thirty nine student-teachers were participated in responding to research questions distributed to them. Of this number of student-teachers, twelve of the students (student-teachers) did not understand the concept of the questions and filled the questionnaire in zigzag form and the result was devalued (discarded). Therefore, a 
random sampling technique was used to get the desired data. Because, the sampling was fortunately taking place on students from different schools (areas) in the region. However, all English language teachers were considered participants in the study, because they were three (small) in number.

In order to collect the relevant information concerning with the assessment of factors that impede the reading comprehension skills of the students, especially inferential understanding, three data gathering tools were used. These were: questionnaires with open and close ended questions, and classroom observation and interviews. Questionnaire and classroom observation were the most instruments used to arrive at the findings-since both were in tightly working with student-teachers in collecting the data. The questionnaire was distributed to large number of participants when relatively compared to interview. In addition; classroom observation was the second instrument that was highly supported the findings obtained through questionnaire. Following this, questionnaire and classroom observation were the principal instruments (tools) used to get the pertinent information in this study. Up on this, the researcher used semi structured interviews as instrument of data collection to get data on the factors affecting studentteachers' reading comprehension practice in English language classes. The most important and pertinent data for Qualitative data was obtained through this types of instrument. This is because, it was most importantly dealing with descriptions. Thus; each English language teacher was interviewed individually to obtain required information through it. Hannan (2007) pointed out that interviews could be used to collect facts and to elicit information about the attitudes, opinions, perspectives and meanings. And also additionally explained that semi-structured interview was widely used in this study because it is a powerful means of both obtaining information and gathering insight. Accordingly, this data collected instrument was preferred to collect information from the three English language teachers. Most importantly semi-structured interviews were used to ask further questions and help to control the direction of the interview to produce the data desired. In this type of interviews, the researcher designed a set of key questions to be raised before the it takes place, and such interviews are often used in education research (Scheurich, 1995).

Besides, semi-structured questionnaire is one of the most popular methods of collecting data in conducting scholarly research. It provides a convenient way of gathering information from a target population (Walonick, 1993). As a result, it was used to collect the data from respondents. This is because the questionnaire was used to gather quantitative and qualitative data that deals with numerical expressions and also descriptionrespectively to obtainpertinent information and further explanations, especially useful in the open-ended section of the questionnaire. However, the close-ended forms of questions helped to gather important data through the controlled nature of the questions and some of the questions were adapted from other research which had similar concepts to the one studied here although most of the questions where produced by the researcher. As a result, five open-ended questions and twenty close-ended questions were prepared and distributed to the student-teachers to get valuable information from them. These questions played an important role in answering the research question addressed in the study.

Thirdly, Classroom observation helped the researcher in getting qualitative data that deals with description. (Fahri,

2003) pointed out that the purpose of systematic classroom observation is to identify and quantify the teaching activities in the classroom that may be considered important for a specific teaching procedure. Walkercited in (Stenhouse, 1975) stated that classroom observation has many valid and important educational purposes: description of instructional practice, investigation of instructional equities for different groups of students and improvement of teachers' classroom instruction based on the feedback from the individual classroom or school profiles. Thus, in order to obtain valuable data and relevant input on the factors affecting studentteachers' inferential understanding in reading for comprehension practice in English language classes, semi-structured observation check lists were designed. As result, the three English language teachers were observed by using the checklist designed.

In this study, two forms of data were generated - qualitative and quantitative. The qualitative data were used to analyze the information obtained through interview and open-ended questions. Thus, the data were discussed, interpreted, summarized and analyzed qualitatively. The quantitative approach was used to analyze the data gathered through classroom observation and close-ended questions. Because, these questions were provided to the respondents with limited choices, these alternatives were quantified. Finally, quantitative and qualitative data were integrated through the expressions of numerical values that is percentage, frequency with relating description of the data, respectively. Then, related reviews were used to strengthen the idea of the findings to form the holistic picture of the analysis.

\section{Results and Discussion}

This part of the study is devoted for data presentation, analysis, interpretation and also the discussion in order to attempt to answer the research questions raised. The findings from the quantitative and qualitative data were integrated and discussed in light of relevant empirical and theoretical works, such as percentage, and descriptions for each. 
The main factors that affect student-teachers' inferential understandings were: lack of frequent practice in the classroom and no reading experience in high school-poor back ground knowledge in practicing for reading for inferential understanding-reading for hidden meanings as implied meaning. Secondly, most teachers were not prepared to come up with reading texts that would help the students to practice reading for inferential meaning. However, in a rare case they brought small paragraphs that target reading for stated meaning to the class. Hence, Student-teachers were not always practicing reading for inferential understanding during reading comprehension activities and hence they did not develop a culture for such practice.

On the other hand, an interview made with the three English language teachers namely Mr.Tadese, Habitamu and Bizuayiew revealed that "student-teachers have poor reading experience in extracting inferential meanings; this is due to mainly lack of regular practice and lack of attention towards implied meanings."

The study showed that large number of students with in learning class or in the language class were accommodated and small class size were the hindering factors that created problems on students' failures in reading for inferential understanding. Besides, the result of interview from English language teachers meet along the same line about the negative impact of classroom size on students learning teaching process with particular attention to weaker ways of learning in reading for inferential understanding in practicing reading comprehension. "---Since large numbers of students were in a single class, it has become difficult for the teacher to treat all students within an hour during delivering the lesson. Besides, classroom size affects the teaching learning process since the teacher faced problems in facilitating students' participation, identifying learners, in using teaching aids effectively to motivating students for reading comprehension."

In addition to these limitations with regard to class room size, the physical environment was the other factor that affected students reading ability in the school environment. Barbara (2006) stated that "Heat and cold have been found to affect learning since the brain is the master control center for the body. When it is too cold or too hot, the brain is constantly reminding the body to do something about this condition. It will be difficult for the student to focus on his or her lesson because every minute or so, the brain will be sending messages. An interview made with English language teachers verify that the temperature of certain environment has its own positive and negative impact on teaching learning process. When the temperature is hot it has become difficult to teach and manage classroom conditions effectively, rather it created some difficulties in doing so".
In line with this, (Duke and Pearson, 2008) also states that "students should be allowed to get a sweater if needed. Teachers could keep sweaters in the room for this purpose. If the temperature is not improved, the brain will continue to interrupt thinking until it is. Windows could be opened between classes or during recess to control temperature and prevent those close to the windows getting too cold.

According to the informants view,physical environment is one of the impediment that affected students learning in general and the reading practice in particular. Therefore, high temperature made it difficult to treat students in the class individually or even in groups. During the warmest season, students were unable to attend their lessons regularly.

As a result, based on the above findings it is possible to generalize that the effect of classroom size, the physical environment-high temperature and lack of commitment of English language teachers affected student-teachers knowledge of inferential understanding and its practice and in turn these variables affected the ability and habits of student-teachers' inferential understandings in the reading comprehension texts.

Finally, it could be possibly concluded that factors affecting student-teachers' inferential understanding in reading comprehension were lack of regular practice in English classes, lack of motivation due to the impact of practice, effect of large class size and also the effect of physical environment. Then, it was hardly possible that students could be active participants in reading for inferential understanding; but the evidences lead to predict that student-teachers were not often practicing in reading for inferential meanings. And therefore, this premise helps judge that student-teachers never practiced reading for inferential meanings.

The study revealed that inference is the reasoning involved in drawing conclusions based on evidence and prior knowledge rather than observation. When inferring, students must draw conclusions when the answer is never clearly stated. They bring personal meaning to the text by connecting it with prior knowledge. Students must use hints or clues in the text or data to figure out the best solution.

An interview made with one of the English language teacher could be narrated as follow, which would be expected to strengthen the above idea, obtained through questionnaire--"In my teaching experience, I have observed that students did not have good background knowledge in reading and they often did not understand inferential texts. They were not motivated to read the texts given to them. They have had little reading comprehension practice in high school. This showed that teachers were not always trained them for inferential meanings. But, good background knowledge contributes to learning potential while reading for 
inferential meaning. Prior knowledge is duly important because it includes the knowledge, skills and abilities that students bring to the learning process and include both declarative and procedural knowledge. As noted by (Amber, 1996) essential to comprehension is the process of relating to prior knowledge - the ability to integrate new information with previous life experience and texts read.

In reading for inferential understanding effectively, students need to integrate new material with their existing knowledge base, construct new understanding and adapt existing concepts and beliefs as needed. Proficiency at these tasks is essential to literacy (Ediger, 1994). However, students who lacked sufficient background knowledge or unable to activate this knowledge, and might struggle to access content where reading to learn is a pre-requisite for success.

As it is revealed in the above discussion parts, background knowledge is an important input that helps them to be active in reading; this involves expectation, prediction of main points of the reading material by using past experience and knowledge. Therefore, background knowledge can be categorized to two parts -formal schemata-involving Knowledge of rhetorical structure and conventions and content schemata - involving knowledge of the world beyond the text (Amber, 1996). Again this result is supported by the findings obtained in the classroom observation and an interview made with the informants in the department. Student teachers did not have good opportunity of practice, experience for practice and the involvement of English teachers in assisting students in practicing reading for inferential understanding was insignificant. In spite of these limitation, the more we read and learn about the topic, the easier the next passage on that topic will be for us to understand. From a reader-response constructivist perspective (Back, 2002), understanding what is read is related to the individual's experiences and interpretations of these experiences. This subjective component makes for a dynamic interaction between the reader and the text. Thus, what readers learn or how they respond to text is individualistic.

\section{Major Findings}

Findings indicated that lack of frequent practice independently was one of the problems for extracting inferential meanings in reading comprehension-The study revealed that this problem was emerged from lack of motivation towards reading for inferential meanings; poor high school background knowledge about reading comprehension. Besides, the impact of class size, the physical environment (high temperature) of the area and lack of teacher's commitment in designing or preparing authentic reading materials and in supporting studentteachers were the other impediment for the absence of practice in English language classes. Loss of attention towards inferential meanings and also poor reading strategies were the other factors found in the study.

Additionally, the findings showed that these factors were affecting student-teachers reading for inferential meanings negatively. This is because those student-teachers did not have regular practice, due to the effect of background knowledge, lack of motivation, effect of class size and also physical environment, they would not be effective in reading comprehension in general and in extracting inferential meanings in particular. Consequently, those teachers would not be effective in critical reading ability and become poor in understanding inferential meanings.

\section{Recommendations}

Based on the data analyzed and the conclusions drawn from the analysis the researcher forwarded the following recommendations.

Student-teachers should spend almost much of their class time in practicing reading comprehension activities either independently or in groups that could facilitate the development of the knowledge for inferential understanding. They should be committed or experienced of using different authentic reading materials that would alleviate the problems hindering their readings abilities for inferential understanding.

Student teachers would effectively achieve their reading for inferential understanding by the active involvement of teachers from high school and also in colleges. They should be committed enough in making students to practice reading for inferential meanings. The commitment of teachers would be facilitated in providing different incentives. This would make the teachers motivated in supporting their students learning. This in turn could facilitate and increase students' motivation towards reading for inferential understanding. Creating opportunities to student teachers to practice reading by using different reading strategies. The classroom teacher should be strong enough in developing students' background through the habits of reading. Because, inferential meanings require a certain support of classroom teacher since the meanings are not directly stated in the text, but it is hidden message and sometimes requires investigations by referring further beyond the writer. Therefore, the classroom teacher is supposed to deal with key-points, background of the text and some interpretations so as to make efficient readers in understanding inferential meanings.

Moreover, the responsible bodies-the Dean and Academic dean in college should take the learning responsibility to prevent some hindering factors that would affect and challenge the development of learning out comes in the learning classes. Therefore, those represented bodies of the college should play a great role in resisting the challenges. For instance, organizing the condition about the presence of 
ventilator to overcome the problem with related to the physical environment- harsh temperature of the area; besides, building more learning class that would surely alleviate problems related with the class size. Finally, these representative bodies of the college should be strong enough and committed in supervising, and facilitating English language teachers so as to create conducive environment in supporting, motivating in preparing authentic learning materials, and in taking practice as part of regular teaching learning process in order to reduce the degree of the problem on student-teachers, learning achievement in the learning class.

\section{Acknowledgement}

First, I would like to express my greatest and deepest appreciation and affection to Dr. Jaylan Wolyieand Dr. AdinewTadesse for their humanitarian commitment in advising me till the end. Secondly, I would like acknowledge Mr.AlebachewGida and Mr. Atnafu Morka in encouraging me to work hard in engaging on this kind of professional contribution to have professional linkage with worldwide.

\section{References}

Amber D (1996) The Effects of Activating prior Knowledge before Reading on Students with and without Learning Disabilities. Pittsburg State University press

Back S (2002) Reading Comprehension Skills and Strategies. Cambridge: Cambridge University Press.

Barbara P (2006) How Hot and Cold Temperatures Affect the Brain. The Brain Demands The Body Cool Itself - ablestock.com
Duke KN and Pearson DP (2008). Effective practices for developing reading comprehension. The Journal of Education, 189(1/2): 107-122.

Ediger A (1994) Reading for meaning. Skills Development for Active Reading. New York: AddisonWeseypub.Co.

Fahri K (2003) The Effects of Class Size and Learning Style on Student Performance in a Multimedia-Based Marketing Course.

Girma Tadese (1994).An Assessment of Effective Reading Strategies in English language Classes. Unpublished:Addis Ababa University.

Hannan A (2007) Interviews in Education Research. Hannan Faculty of Education. University of Plymouth:

Klingner JK, Vaughn S and Boardman A (2015) Teaching reading comprehension to students with learning difficulties, 2/E. Guilford Publications.

Lenz K (1999)..Reading Comprehension. Understanding process: University of Kansas.

Nuttal C (1996) .Teaching Reading Skills in Foreign Language. London: Heinemann.p.21.

Scheurich J (1995) Education Research in Post modernism. Falmer Press, 243p

Stenhouse H (1975) An Introduction to Curriculum and Development, Methodology. London, Heinemann.

Walonick D (1993) Everything you want to know about Questionnaire. Stat Pac: Research Liberary, Retrieved on May 24, 2011 